\section{The Whitehead Correspondence}

The Whitehead correspondence in the Russell Archives extends from 1895 to 1944, with the bulk of the 102 letters dated between 1903 and 1910. A few of the letters discuss topics of general interest; there are, for example, letters from Whitehead in which he criticizes Russell's views of the First World War. There are also some points in the letters of interest to students of Whitehead's later metaphysics. For instance, on April 26, 1904 Whitehead asked:

Does God intuit propositions as a series of ideas? Perhaps he thinks of $x \in \times$ all at once as a proposition about $\mathbf{x}$.

This indicates that even at this early date Whitehead was considering the possibility that God might have two aspects, temporal and a-temporal, a view crystallized in his later distinction between the primordial and consequent natures of God.

But the great majority of the letters are concerned with logical topics and with the construction of Principia Mathematica, and these are of interest to, and importance for, students of the history of logic. They enable us to date with a good deal of precision certain important decisions made during the construction of Principia, and to determine to some extent the relative contributions of Whitehead and Russell to this great enterprise.

We know that a good part of Principia was written in a three-step process: (1) Russell wrote an initial draft, which he sent to Whitehead; (2) Whitehead criticized and, if he thought it necessary, revised Russell's draft; and (3) Russell wrote the final draft. (1) There were, of course, many direct conferences, and Russell later remarked that Whitehead had contributed to every page of the book.(2) Many of the letters from Whitehead concerning logical subjects appear to be covering letters he wrote when returning various drafts to Russell.

One general theme running through the Whitehead letters is constant praise for Russell's efforts, praise which must have been a comfort to Russell in those trying years. In May 1903, Russell believed he had solved the contradictions besetting logic by defining classes in terms of propositional functions. Whitehead immediately responded with a telegram (dated May 21st): "Heartiest congratulations Aristoteles Secundus; I am delighted." (As it happened, the congratulations were premature.) In April 1905, after two years impasse due to the contradictions, Russell began to make progress in the theory of denoting. Whitehead wrote on April 23rd: "Your work is admirable. I think that you are in sight of land." Then, in 1907, there are Whitehead's comments on Russell's solution to the question of extensionality in Principia. Roughly speaking, to adopt the "extensional" standpoint in a logical system is to work only with classes, classes of ordered pairs, and truth functions, whereas to adopt the "intensional" standpoint is to work with properties relations, and functions in general, defining classes and classes of ordered pairs in terms of these. Most mathematicians adopt the extensional standpoint, but there were reasons why Whitehead and Russell wished to avoid it: their general suspicion of classes, their desire to have at hand the greater generality of the intensional standpoint, and their wish to use the Peano notation which appeared to favour properties over classes. Russell broke this jam by developing a function which took extensional or intensional functions as arguments and yielded an extensional function as its value. Whitehead commented, on June 16th, 1907

Your transition from intension to extension...is beyond all praise. It must be right.

That peculiar diffculty, which has worried us from the beginning, is now set-

tled for ever.

Whitehead's steady support for Russell as evidenced in the letters may help to neutralize the impression Russell leaves in his Autobiography (Vol. I, London:Allen \& Unwin, 1967, p. 150) that Whitehead in those years was unstable, possibly suicidal, and in constant need of support (including financial) from Russell.

On the other hand, Whitehead was frequently critical of Russell's general approach, and these criticisms indicate some tensions in their partnership. In these years, unlike the late 1920s, Russell was the more philosophical and Whitehead the more mathematical of the pair. Russell viewed Principia more as a criticism of the whole of mathematics; Whitehead saw it more as a systematization of that whole. Russell was more inclined to develop lines of attack on the basis of philosophical preconceptions, Whitehead more in clined to temper these attacks by bringing them into relation with actual mathematical practice. For example, in 1904 Russell was engaged in one of his periodic attempts to abolish class notation from Principia (his other attempts were in 1903 and 1906). Whitehead wrote in criticism:

Now this extreme rigour must be tempered by practical considerations. Classes can be kept in common use by the consideration that our object is to systematize the actual reasoning of mathematics; and this actual reasoning does in fact employ classes habitually when it need not do so. Thus our object is to systematize the reasoning involving classes, even when it is a primitive idea which might be avoided. (April 30th, 1905)

To get a better feel for the way Whitehead and Russell interacted in the Principia period one must turn to more specific issues. Two that are especially constructive are the discussions in Whitehead's letters of the axiom of infinity and Russell's substitutional theory of classes and relations.

In 1903 the Columbia mathematician C.J. Keyser had argued that current theories of transfinite arithmetic all presupposed the existence of at least a denumerably infinite number of individuals. (3) He suggested that this presupposition be made explicit in a separate axiom which he called "the axiom of infinity". In 1904 Russell responded to Keyser (4), agreeing that the theory required an infinite number of entities, but contesting Keyser's view that this requirement needed a special axiom. No axiom was needed, Russell argued, because it was possible to demonstrate a priori that there are an infinite number of entities: first, take the null class, then the class containing the null class, then the class containing both the null class and the class containing the null class, and so on.

This proof gives every appearance of pulling rabbits out of a hat, and it is not surprising that Whitehead was suspicious of it. On April 23, 1905, he wrote to Russell :

Does not the theory require the explicit recognition of (at least) an indefinite plurality, if not of the definite cardinal numbers!

Such remarks, apparently, led Russell to reconsider his position, and eventually he concluded that Keyser was right. This was more than Whitehead had asked or bargained for, and he wrote to Russell on May 9th, 1906: "But I don't like to have to assume as a Pp $\aleph_{0}$ entities, nor blocks of $N_{0}$ Pp's." Ultimately Whitehead must have swung around, for the axiom of infinity (not in Keyser's form but in a form logically equivalent to it) is $\$ 120.04$ of Principia.

Russell's substitutional theory of classes and relations is first mentioned in un published papers now in the Russell Archives from November of 1905.(5) It was first publicly presented in a paper called "On the Substitutional Theory of Classes and Relations" which Russell read before the London Mathematical Society in April 1906. In this paper Russell introduced the notion of a matrix, which was (supposedly) a purely linguistic device designed to perform all the functions in mathematics that had previously been done by the assumption of classes. Given a proposition $\mathbf{p}$ containing a constant $\mathbf{a}$, one matrix that can be developed from $\mathbf{p}$ is "the result of replacing a in $\mathbf{p}$ by" - a linguistic fragment that is not even a complete syntactic unit and becomes meaningful only in a proper context.

Russell originally intended to write the whole of Principia in terms of matrices rather than classes. Had this been done, Principia would look considerably different than it now looks. But Whitehead's veto of the substitutional theory was swift and definite. On February 21st, 1906 he objected to the symbolism of the new theory, and continued,

I look on these remarks as a protest against your excessive formalism. There's

a conversion of heart for you! 
The next day he wrote:

It founds the whole of mathematics on a typographical device, and thereby directly contradicts the main doctrines of Vol. I.

Whitehead got his way, though apparently only after Russell had discovered that the substitutional theory became very complex when the notation for matrices was integrated into the theory of types. By 1907, Whitehead and Russell had adopted the compromise found in Principia - class notation is contextually defined and the ontological commitment to classes avoided (thus satisfying Russell's philosophical biases), while at the same time the definition of class notation comes very early in the book and is used throughout the system (thus satisfying Whitehead's mathematical orientation).

One major question still open is whether or not some parts of Principia are principally the work of one of the two men, with the other making only minor suggestions. The letters leave the impression that some parts of Volume III were almost wholly Whitehead's work. There are also various star numbers which must be from the projected Volume IV for example, Whitehead wrote on September 22nd, 1910 that "The beginning of Geometry is going beautifully - 7500 on Associated Symmetrical and Permutative Triadic Functions is a picture", and this is consistent with the view that Whitehead was to write Volume IV him self. But a more careful disentanglement of their contributions awaits a close study of al the materials relating to Principia now in the Russell Archives.

The political discussions found in Whitehead's post-Principia letters are mainly concerned with Russell's support of British conscientious objectors. Whitehead, who had two sons in the War, whereas Russell was still childless, wrote Russell that it would, of course, be best if there were no wars, but when one comes, all citizens have an obligation to lend support to the cause the success of which is the lesser of two evils. Whitehead was quick to add that this disagreement in no way diminished the affection or respect he felt for Russell: the same cannot be said of many of Russell's academic associates during those years. And when Russell was restored to Trinity in 1944, the Whiteheads wrote:

We have just read - in the minutes of the Trinity Council - that you have been reelected to a Fellowship and Lectureship. The minutes also emphasised that the election was unanimous. Our warmest congratulations. It is exactly what ought to have happened.(6)

(1) See Ivor Grattan-Guinness, "An Unpublished Letter from Bertrand Russell to P.E.B. Jourdain", Journal of Philosophical Logic, 1 : spring 1972, 103-10

(2) "Whitehead and Principia Mathematica", Mind, 57: April 1948, 137-8.

(3) "Concerning the Axiom of Infinity and Mathematical Induction", Bulletin of the American Mathematical Society, 9: 424-35.

(4) "On the Axiom of Infinity", Hibbert Journal, 2: July 1904, 809-12; reprinted in D.P. Lackey, ed., Essays in Analysis (forthcoming).

(5) "On Substitution", December 1905.

(6) Bertrand Russell, Autobiography (London: Allen \& Unwin, 1968), II, 257.

Russell is published quarterly by the McMaster University Library Press, Hamilton, Ontario. Subscriptions are $\$ 2$ or $£ 1$ (via airmail) a year. Darlene Booth laid out the issue; Diane Kerss typeset it on the Silhouette equipment, with instructions from George Horner. Quotations from Lord Russell's unpublished letters and mss. are copyright of Res-Lib Ltd. 